\title{
MYCETOPHILID FLIES AS PESTS OF THE CUCUMBER PLANT IN GLASS-HOUSES.
}

\author{
By E. R. SPEYeR, M.A., F.E.S., \\ Entomologist, Experimental and Research Station, Cheshunt, Herts.
}

\section{(Plate X.)}

Severe injury to the roots of cucumber plants has occurred since January of this year (1922) through the attacks of the larvae of certain minute "fungus-gnats" belonging to the family ScIARIDAE. Although such attacks have not been recorded previously by growers of cucumbers, it is more than probable that the flies have been present in glass-houses for a number of years, and that damage arising through their agency has mistakenly been attributed to "eel-worms."

The first serious outbreak was recorded in January, a very large number of potplants having been damaged to the point of destruction in a nursery at Enfield Wash. The matter was taken up, and the causative factor proved beyond doubt to be larvae of Pnyxia (Epidapus) scabiei, Hopk. A description of P. scabiei has been given by Dr. A. D. Hopkins in the Proceedings of the Entomological Society of Washington, vol. iii, p. 152, in 1895, when the larvae of this fly were regarded as at any rate one of the causes of the disease known as " potato scab."

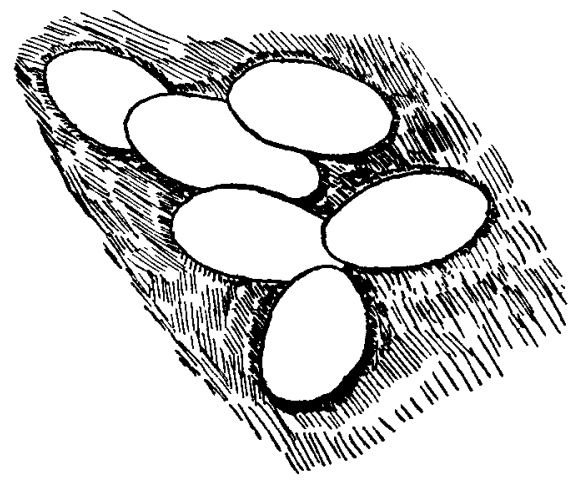

Fig. 1. Pnyxia scabiei, Hopk., eggs, $\times 60$.

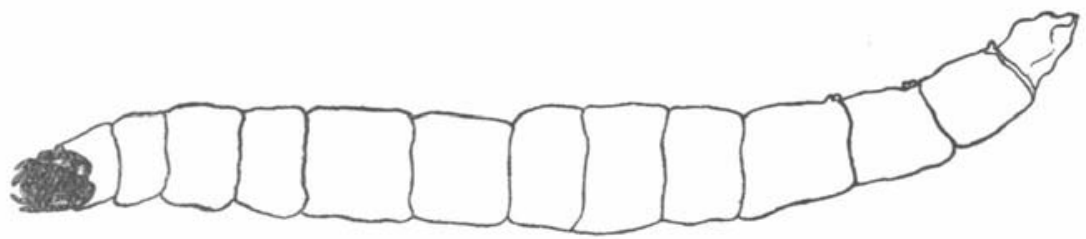

Fig. 2. Larva of Pnyxia scabiei, Hopk., $\times 33$.

As the publication referred to is not readily available, a few of the more important points in the life-history are here taken from Dr. Hopkins's paper. The eggs (fig. 1) are laid by the female fly to the number of 20-30 in soil or manure, and take 5-6 days in hatching. The larvae (fig. 2), which are white with black heads, feed for a period 
of 7-8 days. Finally they spin a cocoon of a dark silky substance, in which they turn to a white pupa (fig. 3 ), the adult fly emerging three days later. The female fly is wingless (fig. 4), and the males are of two kinds, one with long and the other with short wings (figs. 5, 6). The female deposits the eggs 5-6 days after emergence. Broods of flies appear every $20-25$ days.

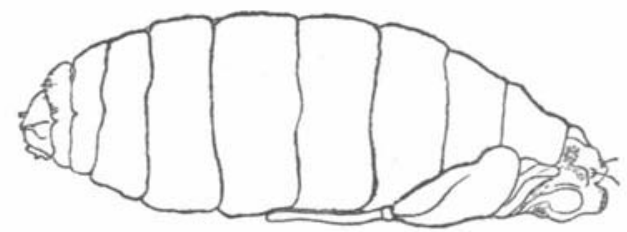

Fig. 3. Pupa of Pnyxia scabiei, Hopk., $\times 33$.

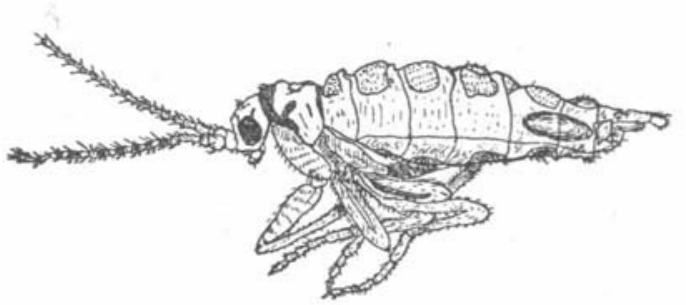

Fig. 4. Pnyxia scabiei, Hopk., 우, $\times 33$.

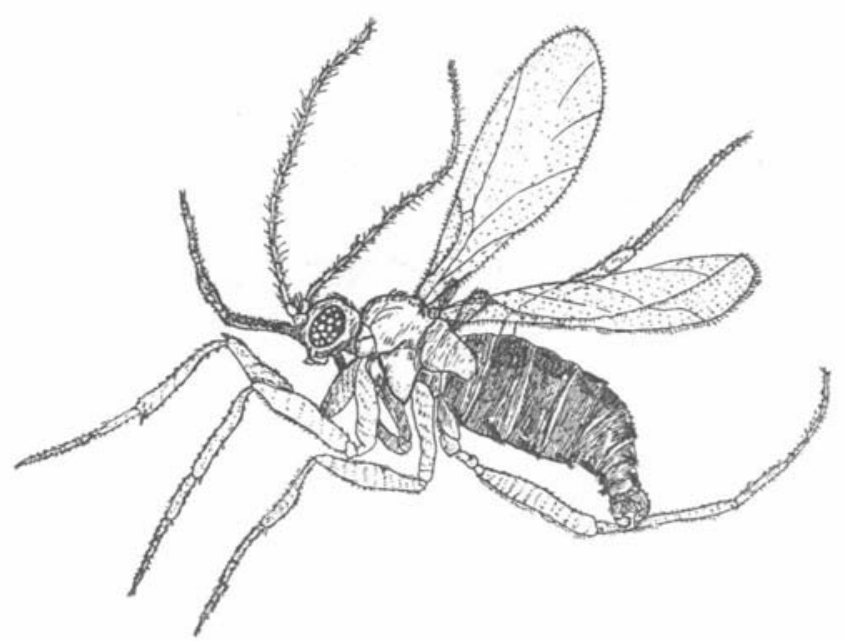

Fig. 5. Pnyxia scabiei, Hopk., ठే, long-winged form, $\times 33$.

Details relating to the attack of Pnyxia scabiei on cucumbers at Enfield Wash are now given.

The cucumber plants were potted out from the seed-boxes (in which there had been no attack) in the middle of December 1921 ; the pot-soil was unsterilised and mixed with horse manure. Attack by the grubs was first noted on 8th January 1922, and between then and 12th January some 600 plants were destroyed. The tap-root of the infected plants had been eaten into by the larvae, and hollowed out from below upwards to within quarter-inch to half-inch below the soil surface. Some root stems contained as many as 60 larvae. On no part of the plant were any eggs found. When full-fed the larvae ate their way out of the stem below the ground and pupated in 
the soil. At this time the soil of the pots was teeming with minute winged flies, which proved to be males of both long-winged and short-winged types.

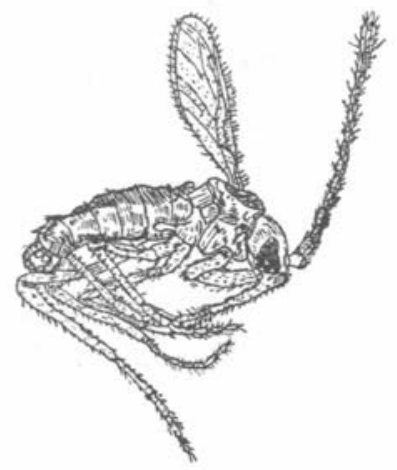

Fig. 6. Pnyxia scabier, Hopk., ðే, short-winged form, $\times 33$.

On 20th January several females made their appearance in the soil of the pots, one being found at a depth of quite 1 in. below the soil surface. Three males and three females were caught in copula and placed in separate glass tubes, one containing moist soil, one horse manure, and the third a piece of cucumber stem without soil.

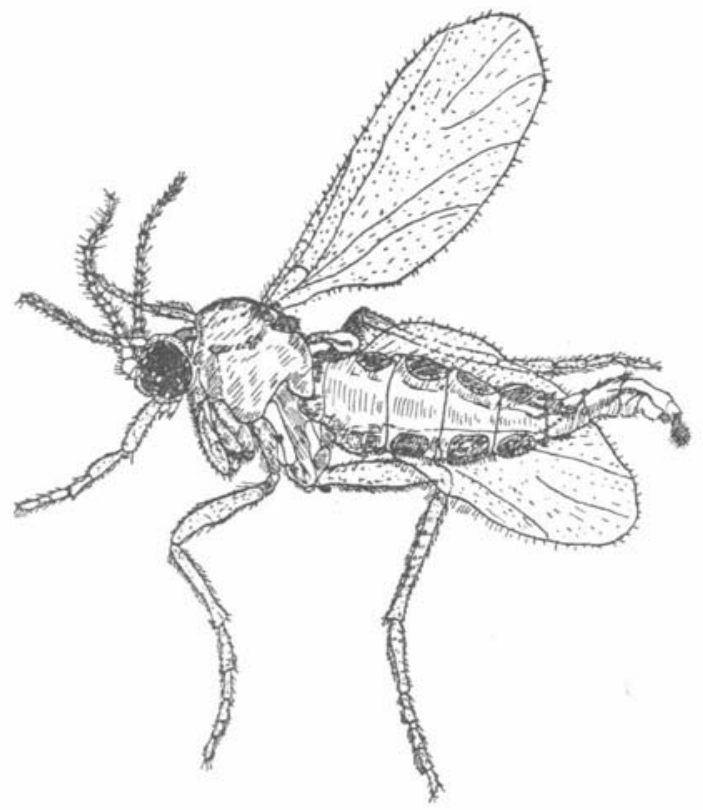

Fig. 7. Plastosciara perniciosa, Edwards, 우, $\times 33$.

All three females had deposited some eggs by 23rd January, but those laid in the third tube had been deposited on the glass, and not on the cucumber stem, and both male and female were dead. In the other two tubes the females lived till the day following, and had then deposited 28 and 25 eggs respectively, a few millimetres below the soil surface. The eggs are oval, white and shining, and measure $0.28 \mathrm{~mm}$. in length.

\section{Conditions conducive to Attack.}

It is now practically certain that the larvae (doubtfully the eggs) are brought into the houses with manure at the time of planting. In more than one nursery in the 
Lea Valley great numbers of flies have been observed shortly after the introduction of the borders in to the houses, yet here no damage has resulted to the cucumber plants.

The attack described above followed on a period when the pot-plants had admittedly been watered insufficiently, and there is no doubt that the larvae are dependent upon a certain moisture content in the soil, a deficiency of which causes them to invade the roots of the plant. In making recommendations for control, it will be seen that an excess of moisture in the soil is fatal to the life of the larvae, but before describing some experiments in this connection mention will be made of another Sciarid fly which has appeared as a severe pest, namely, Plastosciara perniciosa,

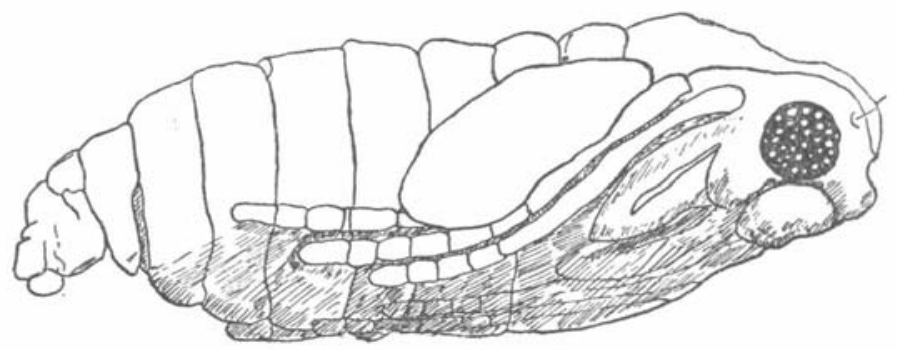

Fig. 8. Plastosciara perniciosa, Edwards, 우, pupa, $\times 60$.

Edwards (Entomologists' Monthly Magazine, July 1922, p. 160). This minute black fly (fig. 7) is very similar to Pnyxia scabiei, but both sexes of the fly have wings. Recently there has been a very serious outbreak in cucumber houses in the Worthing district, and another attack has been reported from Dartford. The attack has been confined to fruiting plants in the border, the hundreds of larvae having reduced the tap-root to a pulp, and caused much further damage by removing the cortex of the stem just below, and sometimes even above, the soil surface ( $\mathbf{P l}$. $\mathbf{x}$, figs. 1, 2). The adult flies swarm in the morning, in bright sunlight, and are found in company with Pnyxia scabiei.

\section{Control Measures.}

With a view to killing the larvae in the soil, the following chemicals have been used :-

Potassium sulphide, 2 per cent., 1 per cent., and 0.5 per cent. solution; $100 \mathrm{cc}$. to the pot, 2 applications.

Ammonium carbonate and copper sulphate, 2 per cent., 1 per cent., and 0.5 per cent. solutions; $100 \mathrm{cc}$. to the pot, 2 applications.

Mustard, 2 per cent., 1 per cent., and 0.5 per cent. solutions ; $100 \mathrm{cc}$. to the pot, 2 applications.

Calcium chloride $\quad$. $\quad$. . $\quad$. $\quad 5$ per cent. solution on larvae.

Ammonium carbonate $\quad . \quad \ldots, ", ", \quad$, and on soil.

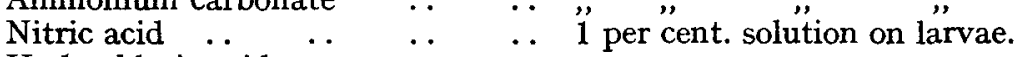

Hydrochloric acid .. $\quad$. $\quad . \quad, \quad, \quad, \quad$ " ,

Potassium bichromate $\quad . \quad$. " " " " " " "

Potassium permanganate .. . , " , " , " , "

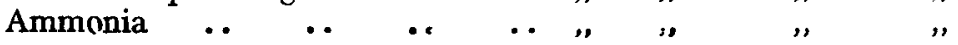

Except for hydrochloric acid, which is dangerous to use on plants, none of these substances gave any appreciable result. During the experiments, however, some larvae were immersed in water, and it was found that they died in about an hour's time. 
Accordingly, three infested pot-plants were placed in a pail, and water was added so that the surface of the soil was just covered. A number of adult flies floated to the surface and were unable to rise from the water. After immersion for 12 hours the plants and soil were examined, and no living larvae could be found. A number of larvae had left the pots and were dead at the bottom of the pail. Fresh plants were then planted in the soil of these pots, but no further attack resulted. In consequence immersion of the pots was at once carried out on a large scale, with entirely satisfactory results.

The larvae of Plastosciara perniciosa are as susceptible to moisture conditions as those of Pnyxia scabiei. Cucumber roots containing many thousands of larvae were placed in large pots with soil from the cucumber border in which the plants had been growing. Some pots were watered so that the soil was of the consistency of a pudding, while others were kept well on the dry side. After three days the soil was examined; the larvae in the wet pots had left the roots and about 98 per cent. of them had perished, while in the dry pots no dead larvae could be found. At the same time, in both cases where the attack had broken out favourable reports were received from the growers, and an improved condition resulted in the health of attacked plants after heavy watering had been carried out. 

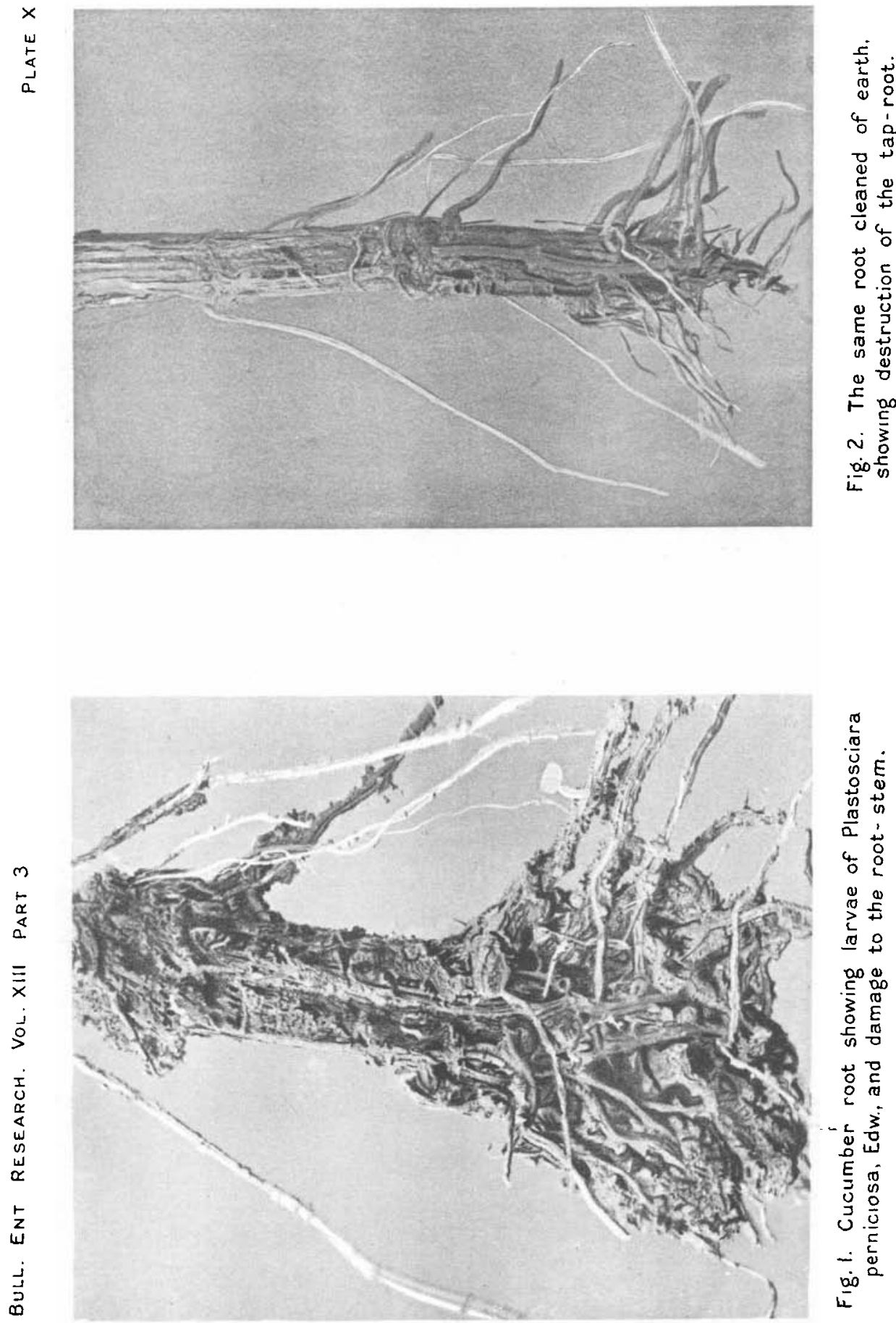